\title{
A Cyto-histopathological Analysis of Oral Mucosal Lesions : with Special Reference to Clinical and Flow Cytometrical Findings
}

\author{
Sisilia Fusi Fifita, and Kayo Kuyama
}

Department of Oral Pathology, Nihon University School of Dentistry at Matsudo, Matsudo, Chiba 271-8587 Japan

Correspondence to :

Sisilia Fusi Fifita

E-mail : fsisilia@hotmail.com

Keywords :

oral mucosal lesions, clinical findings, exfoliative cytology, clinico-histopathology, flow cytometry, misdiagnoses

\begin{abstract}
In order to evaluate the diagnostic accuracy of exfoliative cytology (EC) in oral mucosal lesions (OML), we studied it and compared with histopathology, clinical findings and flow cytometrical analysis (FCMA). Two hundred and seventy five smear cases were obtained from 40 normal tissue samples (control) and OML; leukoplakia (187), exophytic epithelial tumor or verrucous carcinoma (EET or VC) (8) and oral squamous cell carcinoma (OSCC) (40). As for FCMA, the DNA and proliferative indices (D.I. and P.I.) of all cases including the misdiagnoses were calculated. In leukoplakia without dysplasia, the accuracy rate of EC diagnosis was $70.0 \%$, while leukoplakia with dysplasia was $26.7 \%$ for mild, $47.6 \%$ for moderate, and $84.2 \%$ for severe cases, respectively. All EET were misdiagnosed by EC, while OSCC had a 100\% accuracy rate. The sparsity of atypical cells, which mostly contributed to the discrepancy in EC diagnosis of the underdiagnostic cases. Erythema, ulcers, Candida, nodular outgrowths and increased number of atypical cells that contributed to the over-diagnostic cases. The mean D.I. of leukoplakia without dysplasia was 1.8 , while mild, moderate and severe dysplasias were 2.2, 3.5 and 3.9, and EET or VC and OSCC were 4.3 and 4.5, respectively. The P.I. values also showed the same tendency. Overall, 96 cases were cytologically misdiagnosed where 64 cases were under-diagnosed and 32 cases were over-diagnosed. Exact evaluation was made by flow cytometry (FCM) in 77 of 96 misdiagnostic cases $(80.2 \%)$ of EC. Accurate diagnosis of OML especially oral epithelial dysplasia by clinical and cytological findings is still difficult to achieve. Mild and moderate dysplasias had lower accuracy rate compared to severe and OSCC cases. Main problems for under-diagnosis of dysplasia include limited number of atypical cells and for over-diagnosis include clinical and cytological findings. The FCMA of leukoplakia without dysplasia and mild dysplasia were significantly close, while EET or VC cases were closer to OSCC results. FCM gave significant results for all EET or VC cases. The authors conclude that FCM, though not a replacement for standard cytological examination or biopsy, would help to lessen the subjective evaluation of OML and in establishing strategies and follow -up protocols for patients with dysplasias and EET or VC. Our studies suggest that combination of EC and FCM is very useful in the evaluation of misdiagnostic cases.
\end{abstract}

\section{Introduction}

Ordinarily, oral mucosal lesions are diagnosed by clinical inspection of suspicious areas and histopathological biopsy (1). The need for early diagnosis and prevention of oral cancer is necessary because of its high morbidity and mortality rate (2). In Japan the Papanicolaou's class system, devised for cervical cytology, and the General Rules for Clinical and Pathological Study of Uterine Cervical Cancer have been adopted for the diagnosis of $\operatorname{OML}(3,4)$. In most 
of the early reports, the benefits of exfoliative cytology in diagnosing cancer are emphasized $(5,6)$. However, there has been controversial discussion about the value of EC for the detection of oral epithelial dysplasia (7). Oral keratinization can mask premalignant and malignant changes in the underlying layers of the epithelium and therefore EC is sometimes difficult to accurately diagnose the dysplasia (8). The screeners and pathologists are responsible for establishing an accurate cytological and histopathological diagnosis before instituting treatment.

Although a number of techniques are being used to study the dysplastic grading of OML, only a few methods using oral smears to assess the risk for OML have been presented (9). Biopsy has been the only reliable method for diagnosis of OML (10). Flow cytometrical analysis is the scanning of a cytology sample and nuclear staining, which can bind DNA with the resultant generation of fluorescent signals, thus, facilitating the identification of special groups of tumor cells and their volume (11-13). Aneuploidy by FCMA refers to an abnormal number of chromosomes; it is associated with reactive or inflammatory lesions, epithelial dysplasia and malignancy (14, 15). Schwartz et al. reported the use of EC and FCM to assess the changes of DNA content of oral squamous cells of both smokers and non-smokers, although there was no comparison of cytology, histopathology and clinical findings to FCMA (16).

Therefore in this study, the accuracy of EC in the diagnosis of OML was compared with histopathology and clinical findings. Also, the DNA and proliferative indices by FCM in relation to cytological and histopathological findings as well as misdiagnostic cases were studied.

\section{Materials and Methods}

\section{Smear specimens}

All cases were selected during oral examinations at the time of their first visit to Nihon University School of Dentistry at Matsudo. From each OML, cells were exfoliated using Cytobrush (Medscand Medical, CoperSurgical Company, Berlin, Germany).
The protocol was approved by the Committee of Studies Involving Human Beings of Nihon University School of Dentistry at Matsudo (EC 05-002). Informed consent was obtained from all patients before taking the cytological smears.

\section{Cytological assessment of smears}

Each patient's mouth was first rinsed with water once to remove food debris and moisten the surface. To obtain a smear, the cytobrush was rolled at least 5 times with gentle pressure. The clinician took two sets of smears for each patient. The first set was smeared on labeled glass slides, immediately fixed in 95\% ethyl alcohol, and subsequently stained by the Papanicolaou method for cytological diagnosis (2).

The diagnoses were made according to Papanicolaou's classification and General Rules for Clinical and Pathological Study of Uterine Cervical Cancer in Japan (3, 4). Diagnoses were classified as : Class I: no neoplastic cells identified; Class II : atypical cells present but no neoplastic cells identified; Class III : atypical cells suspicious for malignant cells present; Class IV: atypical cells highly suspicious for malignant cells present; Class $\mathrm{V}$ : malignant cells identified.

The second set of smears was performed on the same identical site and was immediately placed into a $1.5 \mathrm{ml}$ conical tube containing di-methyl sulfoxide in sucrose-citrate buffer for FCMA (CycleTESTTM PLUS DNA Reagent KIT, Becton Dickinson, California, USA). Forty volunteers with normal buccal mucosal smears were used as the control with a mean age of $40.8 \pm 10.4$ years, and consisted of 25 females and 15 males. These volunteers were nonsmokers, non-denture wearers, had not consumed any spicy or hot foods or rinsed with mouthwash before smears were taken. The same procedure was performed for the control smears using Papanicolaou method and FCMA.

\section{Clinical assessment}

All smears, plus those with histopathological findings, were assessed by 1 or 2 pathologists, a cytological screener and a clinician at the time of 
smear taking. The clinical assessment of leukoplakia was performed according to WHO clinical classifications of 1997 and $2005(17,18)$.

\section{Histopathological assessment}

Tissue specimens from both biopsy and operational materials of the OML were routinely stained with hematoxylin and eosin and subjected to histopathological examination. Both histopathological and cytological diagnoses were compared and the accuracy rates were calculated. The accuracy rate was calculated by the percentage of the cytological diagnoses that matched histological diagnoses. The non-matching cases were referred to as under- or over-diagnosed by EC. In addition to these discrepancy cases, the factors of misdiagnoses ; cytological and clinical findings were analyzed.

\section{Flow cytometrical assessment : DNA content}

For the FCMA, all cases were included together with both under- and over-diagnostic cases. To prepare single-cell suspensions for FCM, the cells were stained with propidium iodide (19). Cell cycle analyses were performed using a Cycle TEST PLUS DNA Reagent Kit (Becton Dickinson and Company, California, USA) and data was analyzed using CellQuest software and ModFit LT (Verity Software House, California, USA). The DNA content was evaluated for ploidy, in relation to cell cycle, and a summary of D.I. (mean \pm standard deviation) and P.I. (\%) was recorded. The D.I. is a quantitative term used to ascertain whether a certain population of cells falls within the normal diploid range. It is expressed as the ratio of the peak channel number of a DNA aneuploid $G_{0} / G_{1}$ cell population to normal $\mathrm{G}_{0} / \mathrm{G}_{1}$ cells of the same sample investigated. In diploidy D.I. $=1 \pm 0.1$, and D.I. out of the above range was aneuploidy. The P.I. was calculated as the sum of the activities of the $S$ and $G_{2}+M$ phases of the cell cycle, expressed as a fraction of the total cell population. It is used to indicate tumor proliferation (20). The FCM results of all smears and under- and over -diagnostic cases by EC were compared.

\section{Statistical method}

D.I. and P.I. were analyzed statistically using Welch's test $(\mathrm{p}<0.05)$. Discrepancies or misdiagnostic cases were those in which EC findings stated mild, moderate or severe dysplasias or cancer cells when no dysplasia or malignancy was found by histopathology or FCMA (D.I. and P.I.).

\section{Results}

\section{Patient population and clinical findings}

The study population consisted of 235 patients who had been suspected clinically of OML and who had smears taken (Table 1). The mean age of the patients was $53.4 \pm 15.3$ years (range 25-90) and consisted of $54.6 \%$ females and $45.4 \%$ males.

Generally, in leukoplakia without dysplasia, the cases generally had homogenous flat and minimal leukoplakic features without erythema. Leukoplakias with dysplasia generally showed irregular thin to thicker leukoplakic features. Presence of erythema, inflammation, ulcers, nodules and Candida was seen in some leukoplakia cases. EET or VC consisted of papillary growths and heavily whitish patches. OSCC's clinical characteristics were variable; some were severely ulcerative with irregular edges, exophytic and excessive keratin production.

\section{Cytological findings}

The cytological diagnoses are also summarized in Table 1. No cellular or nuclear abnormalities were observed in the smears obtained from the control group. Fifty cases were diagnosed leukoplakia Class II without dysplasia. Overall, nuclear changes in these cases were limited to slight enlargement, however, the features were different from dysplastic change. Moreover, 137 cases were cytologically diagnosed leukoplakia Class III with the presence of dysplastic cells. The changes according to EC diagnosis showed mild, moderate and severe hyperchromatic nuclei with irregular borders, and more orange cytoplasms. All 8 EET cases were misdiagnosed by EC and ranged from Class II with no neoplastic cells, to Class III with a few dysplastic cells. Forty cases were diagnosed as OSCC by EC and 
Int J Oral-Med Sci 6(3):130-139, 2008

Table 1. Oral mucosal lesions according to clinical, cytological and histopathological diagnoses

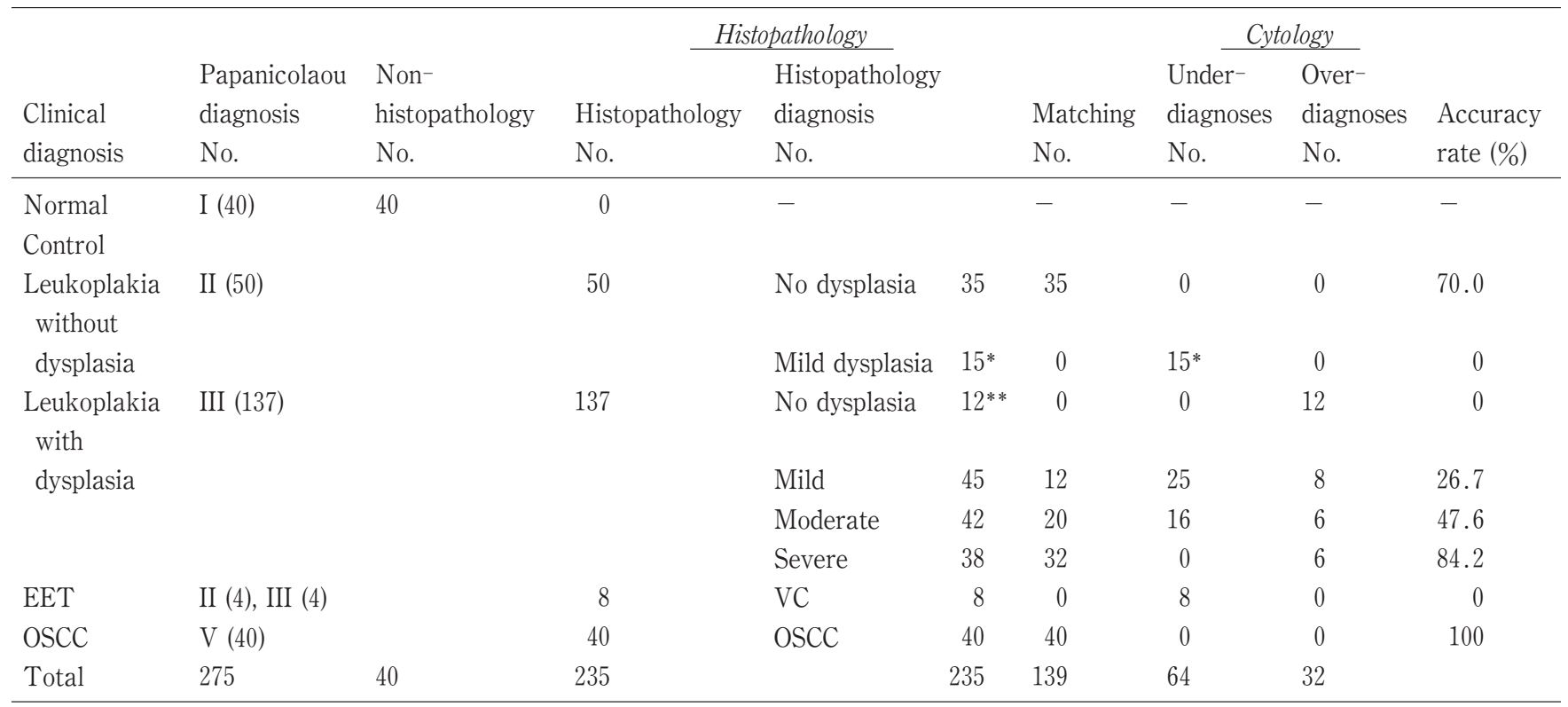

* : 15 cases were diagnosed by EC as no dysplasia but histopahological findings showed mild dysplastic epithelium

** : 12 cases were diagnosed by EC as Class III but histopathological findings showed no dysplastic epithelium

showed the characteristics of carcinoma such as irregular shape, hyperchromatic nuclei and high $\mathrm{N} / \mathrm{C}$ ratio with necrotic background.

\section{Histopathological findings}

The histological diagnoses are also shown in Table 1. Of the 50 cases that were diagnosed leukoplakia Class II without dysplasia by EC (Fig. 1a-b), 15 cases were diagnosed with mild dysplasia by histopathology. The accuracy rate of EC diagnosis was $70.0 \%$. Among leukoplakia with dysplasia Class III, 12 cases were diagnosed with dysplasia by EC, but histopathological findings showed no epithelial dysplasia. These 12 cases were placed in leukoplakia without dysplasia. Overall, the accuracy rate for leukoplakia Class III with mild, moderate (Fig. 2a-b) and severe dysplasia (Fig. 3a-b) was 26.7\%, 47.6\%, and $84.2 \%$, respectively. The accuracy rate for all EET or VC cases (Fig. $4 \mathrm{a}-\mathrm{b}$ ) was $0 \%$. In contrast, the accuracy rate of EC diagnosis in OSCC was $100 \%$.

\section{Flow cytometrical findings}

All cases were divided into two groups. Group 1 included the control cases and the matched cases of EC and histopathology. Group 2 consisted of all the misdiagnostic cases of EC.

\section{Group 1}

Table 2 summarizes the results of this group. The D.I. mean value for control cases was $1.0 \pm 0.3$, and the mean P.I. value was $52.6 \%$. Regarding the leukoplakia without dysplasia, the mean D.I. and P.I. was

Table 2. Values of D.I. and P.I. of normal cases and oral mucosal lesions

\begin{tabular}{lll}
\hline Cases & D.I. (Range) & P.I. $(\%)^{* * *}$ \\
\hline $\begin{array}{l}\text { Normal/Control } \\
\quad \text { Histopathology }\end{array}$ & $1.0 \pm 0.3(0.1-1.2)$ & 52.6 \\
Leukoplakia without dysplasia* & $1.8 \pm 0.8(1.5-2.0)$ & 67.9 \\
Leukoplakia with dysplasia** & & \\
$\quad$ Mild & $2.2 \pm 1.0(1.9-2.6)$ & 70.2 \\
$\quad$ Moderate & $3.5 \pm 0.9(2.9-3.6)$ & 80.9 \\
$\quad$ Severe & $3.9 \pm 1.0(3.7-4.2)$ & 82.7 \\
EET or VC & $4.3 \pm 0.8(4.2-4.6)$ & 84.5 \\
OSCC** & $4.5 \pm 1.0(4.3-4.9)$ & 89.1 \\
\hline
\end{tabular}

$*$ : mean D.I. and P.I. values of leukoplakia without dysplasia were higher than those of control cases $(\mathrm{p}<0.05)$

** : leukoplakia with dysplasia; mean D.I. of mild dysplasia was slightly elevated, while moderate and severe dysplasias were significantly higher and OSCC was the highest $(\mathrm{p}<0.05)$

$*^{* * *}$ : mean P.I. values showed an increase in tendency with upgrading severity of dysplasia 
higher than the control cases. In contrast to leukoplakia with dysplasia; the mean D.I. value of mild dysplasia was slightly elevated, while moderate and severe dysplasias were significantly higher $(\mathrm{p}<0.05)$. The mean P.I. values also showed an increase in tendency with upgrading severity of dysplasia.

Regarding the OSCC cases, the mean D.I. and P.I. values were significantly higher than those of precancerous lesions, especially leukoplakia without dysplasia and mild dysplasia $(\mathrm{p}<0.05)$.

\section{Group 2}

Table 3 summarizes both under- and over-diagnostic cases of EC. A definitive evaluation of mild dysplasia by FCM (D.I. and P.I.) was possible in 10 of 15 cases that was cytologically under-diagnosed leukoplakia Class II. In the remaining 5 cases an exact evaluation by FCM was not possible. Regarding dysplasias, FCMA revealed mild dysplasia in 18 of 25 cases was under-diagnosed by EC as leukoplakia without dysplasia. In the remaining 7 cases revealed leukoplakia without dysplasia was made by FCM (ave. D.I. $=1.7$, P.I. $=65.3 \%$ ). In 16 under-diagnostic moderate dysplasias, exact evaluation of moderate dysplasia was made in 12 of 16 cases. The remaining 4 cases were incorrectly evaluated by FCM. Eight cases of EET or VC were erroneously diagnosed by $\mathrm{EC}$ and correct evaluations were made by FCM similar to histopathological findings. The difference between the D.I. and P.I. values of EET or VC and leukoplakia without dysplasia was significant $(\mathrm{p}<$ 0.05).

Among the over-diagnostic cases, 12 cases of leukoplakia without dysplasia were over-diagnosed by EC as dysplasia Class III. In 12 cases, exact evaluation of leukoplakia without dysplasia was possible by FCM. Eight cases of mild dysplasia were overdiagnosed as moderate dysplasia, 5 were classified correctly by FCM and 3 with unsatisfactory results. Six cases of moderate dysplasia were over-

Table 3. Comparison of under- and over-diagnostic cases of EC with clinical, cytological and histopathological findings

\begin{tabular}{|c|c|c|c|c|c|c|c|c|c|c|c|}
\hline $\begin{array}{l}\text { Cytology } \\
\text { Class }\end{array}$ & Histopathology & $\begin{array}{l}\text { Under- } \\
\text { diagnosis } \\
\text { No. }\end{array}$ & $\begin{array}{l}\text { FCMA } \\
\text { No. }^{*}\end{array}$ & $\begin{array}{l}\text { Clinico-cyto } \\
\text { findings }\end{array}$ & $\begin{array}{l}\text { D.I. } \\
\text { (Ave) }\end{array}$ & $\begin{array}{l}\text { P.I. } \\
(\%)\end{array}$ & $\begin{array}{l}\text { Over- } \\
\text { diagnosis } \\
\text { No. }\end{array}$ & $\begin{array}{l}\text { FCMA } \\
\text { No. }\end{array}$ & $\begin{array}{l}\text { Clinico-cyto } \\
\text { findings }\end{array}$ & $\begin{array}{l}\text { D.I. } \\
\text { (Ave) }\end{array}$ & $\begin{array}{l}\text { P.I. } \\
(\%)\end{array}$ \\
\hline \multicolumn{12}{|l|}{ II } \\
\hline leukoplakia & Mild dysplasia & 15 & 10 & $\begin{array}{l}\text { thin white patches } \\
\text { atypical cells present } \\
\text { with little atypical } \\
\text { features or none }\end{array}$ & $\begin{array}{l}2.1 \\
(2.2-2.6)\end{array}$ & 69.4 & 0 & & & & \\
\hline \multicolumn{12}{|l|}{ III } \\
\hline \multirow[t]{4}{*}{ leukoplakia } & No dysplasia & 0 & & & & & 12 & 12 & $\begin{array}{l}\text { thin to thicker } \\
\text { whitish patches }\end{array}$ & $\begin{array}{l}1.7 \\
(1.5-1.8)\end{array}$ & 65.7 \\
\hline & $\begin{array}{l}\text { Mild } \\
\text { dysplasia }\end{array}$ & 25 & 18 & $\begin{array}{l}\text { thin to thicker white } \\
\text { patches, atypical cells } \\
\text { present but sparse }\end{array}$ & $\begin{array}{l}2.4 \\
(2.0-2.6)\end{array}$ & 72.8 & 8 & 5 & $\begin{array}{l}\text { erythema } \\
\text { ulceration } \\
\text { outgrowth }\end{array}$ & $\begin{array}{l}2.3 \\
(1.8-2.4)\end{array}$ & 68.9 \\
\hline & $\begin{array}{l}\text { Moderate } \\
\text { dysplasia }\end{array}$ & 16 & 12 & & $\begin{array}{l}3.1 \\
(2.9-3.4)\end{array}$ & 78.5 & 6 & 6 & $\begin{array}{l}\text { nodules } \\
\text { many atypical }\end{array}$ & $\begin{array}{l}3.4 \\
(3.0-3.5)\end{array}$ & 78.5 \\
\hline & $\begin{array}{l}\text { Severe } \\
\text { dysplasia }\end{array}$ & 0 & & & & & 6 & 6 & $\begin{array}{l}\text { cells } \\
\text { Candida }\end{array}$ & $\begin{array}{l}3.8 \\
(3.7-4.0)\end{array}$ & 83.2 \\
\hline II, III & $\begin{array}{l}\text { Verrucous } \\
\text { carcinoma }\end{array}$ & 8 & 8 & $\begin{array}{l}\text { thick whitish patches } \\
\text { papillary } \\
\text { atypical cells present } \\
\text { but sparse }\end{array}$ & $\begin{array}{l}4.3 \\
(3.9-4.6)\end{array}$ & 84.2 & 0 & & & & \\
\hline Total & & 64 & 48 & & & & 32 & 29 & & & \\
\hline
\end{tabular}

* : number of under- and over-diagnoses where FCMA classified them correctly and correlated with histopathological findings 
diagnosed, as severe dysplasia by EC, and an exact diagnosis by FCM was possible in all cases. In severe dysplasia, 6 cases were over-diagnosed as OSCC and FCM correctly evaluated the 6 cases was within the ranges of severe dysplasias.

Comparison of misdiagnostic cases of EC with clinical and histopathological findings

Table 3 also shows several consistent clinicocytological features shared by these cases. Among the under-diagnostic cases; 15 were leukoplakia Class II, and histopathology revealed mild dysplasia (Fig. 1c). However, all were homogenous leukoplakia (15 of 15), atypical cells were present but sparse (15 of 15). Regarding dysplasias, 25 mild and 16 moderates cases (Fig. 2c) were under-diagnosed by EC as leukoplakia Class II and mild dysplasia, respectively. The clinico- ${ }^{-}$cytological features revealed a thin to thicker whitish patches. Atypical cells were present but fewer in all cases. In mild dysplasia, erythema (2 of
25) and ulceration (3 of 25) were found in a fewer cases. In moderate cases, the 16 under-diagnostic cases showed erythroplakia (3 of 16), ulceration (2 of 16) and nodularity features (4 of 16).

In contrast, the over-diagnostic cases also shared several consistent clinico-cytological features; all with thin to thicker whitish patches but with some areas of erythema : leukoplakia without dysplasia (8 of 12), mild (6 of 8), moderate (5 of 6). Candida was present in some leukoplakia without dysplasia (7 of 12), mild (6 of 8 ) and moderate cases (4 of 6). Adequate numbers of atypical cells were present in all these cases. In severe dysplasia (Fig. 3c), the 6 overdiagnostic cases shared the features of erythema (6 of 6), ulceration (6 of 6), nodularity (5 of 6 ) and Candida (5 of 6).

In all EET or $\mathrm{VC}$ cases, the clinico-cytological features revealed thicker whitish patches and exo phytic papillary growths but the EC screeners detected fewer dysplastic cells that present in 4 cases (Fig. 4c).
Fig. 1
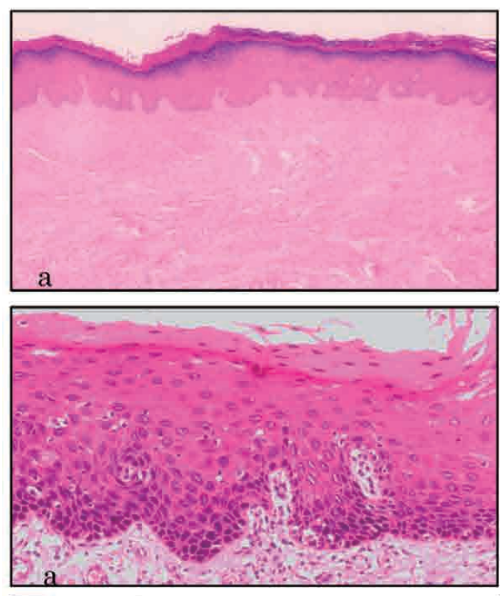

Fig. 2

Fig. 3

Fig. 4
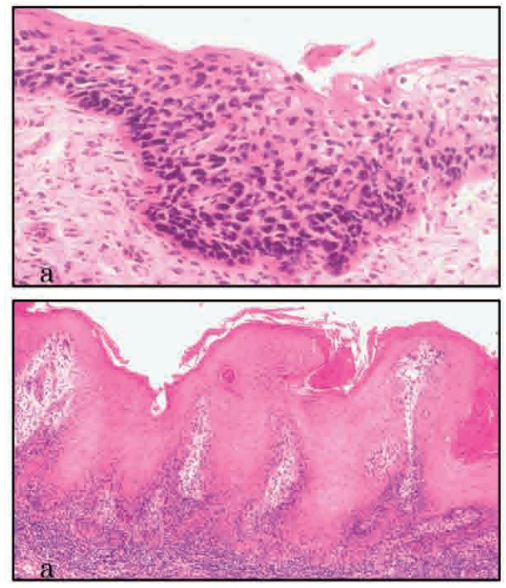
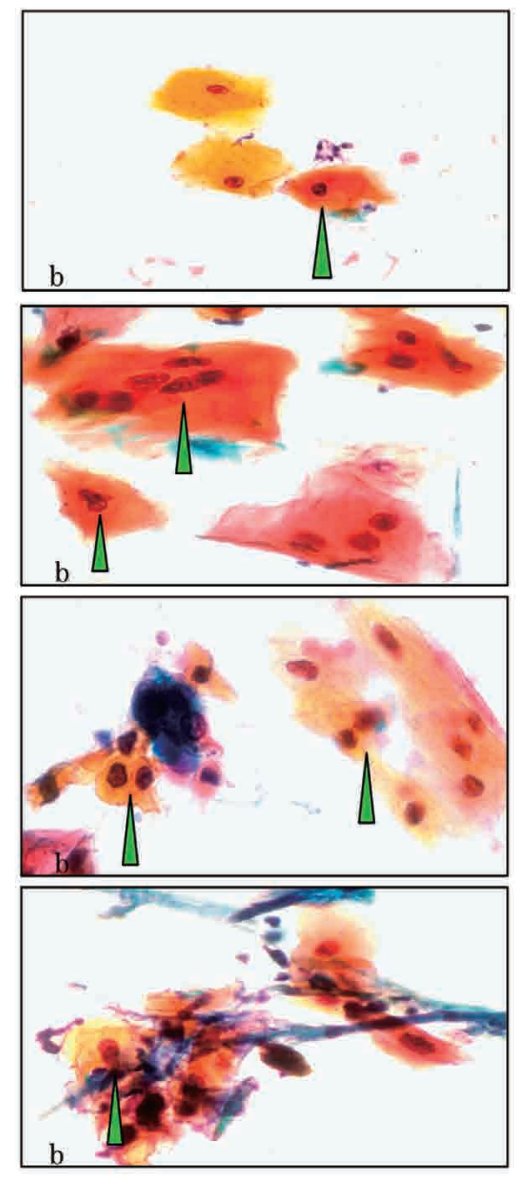
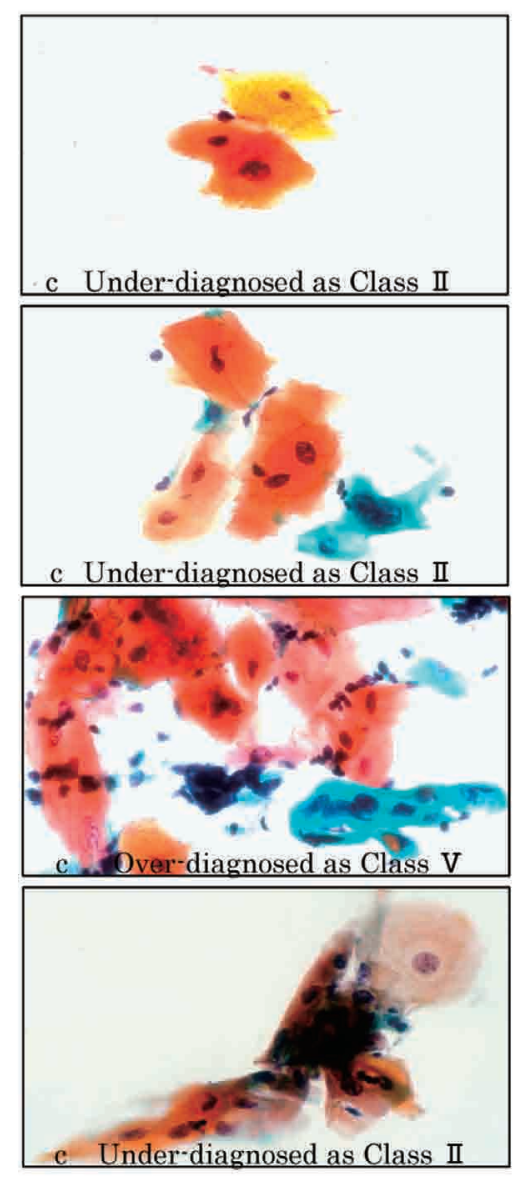
Fig. 1a. Histopathological finding of leukoplakia shows an increased thickness of surface keratin, which overlies a benign stratified squamous epithelium (hematoxylin-eosin $\times 100$ ).

Fig. 1b. Cytological findings show pyknotic nuclei and eosinophilic cytoplasms (strong orange) with no dysplastic feature (arrowhead). It is correctly diagnosed by EC as leukoplakia Class II and matches to histopathological finding (Pap's staining $\times$ 400).

Fig. 1c. It is incorrectly diagnosed by EC as leukoplakia Class II but histopathologically diagnosed as mild dysplasia. Nuclear enlargements with hyperchromasia but fewer atypical cells are present that might cause the misdiagnosis $($ Pap's staining $\times 400)$. Fig. 2a. Histopathological finding of leukoplakia shows moderate dysplasia with atypical epithelial features confined to the lower half of the epithelium (hematoxylin-eosin $\times 200$ ).

Fig. 2b. Cytological finding shows moderate cytological change of nuclei (arrowheads). It is correctly diagnosed by EC as leukoplakia Class III moderate dysplasia and matches the histopathological finding (Pap's staining $\times 400$ ).

Fig. 2c. It is cytologically diagnosed by EC as leukoplakia Class II but histopathological diagnosis is moderate dysplasia. Few atypical cells are present with minor degree of atypism that might cause the misdiagnosis (Pap's staining $\times 400$ ).

Fig. 3a. Histopathological finding of leukoplakia with severe dysplasia showing nearly total thickness and alterations extending to upper third of epithelium (hematoxylin-eosin $\times 100$ ).

Fig. 3b. It is correctly diagnosed by EC as leukoplakia Class III severe dysplasia. Cytological finding shows prominent cytological changes. The nuclei are hyperchromatic with strong orange cytoplasms and abnormal N/C ratio (arrowheads), (Pap's staining $\times 400$ ).

Fig. 3c. It is misdiagnosed by EC as OSCC Class V but histopathological diagnosis reveals severe dysplasia. There are prominent cytological changes and many inflammatory cells that might cause the misdiagnosis $(\mathrm{Pap}$ 's staining $\times 400)$.

Fig. 4a. Histopathological finding of VC (hematoxylin-eosin $\times 200$ ).

Fig. 4b. Cytological finding shows the prominent cytological changes with a few epithelial cells. It is diagnosed by EC as dysplasia Class III. The nuclei are hyperchromatic with strong orange cytoplasms (arrowhead), (Pap's staining $\times 400)$.

Fig. 4c. Cytological findings show atypical cells but fewer to help the diagnosis. It is under-diagnosed as inflammation Class II by EC. The nuclei are hyperchromatic with mildly strong orange cytoplasms (Pap's staining $\times 400$ ).

\section{Discussion}

Although our laboratory has utilized the EC methodology for the examination of oral specimens for over 20 years, the authors have encountered misdiagnosis of OML, especially dysplasia. However, in evaluating the literature, there are hardly any reports available where under- or over-diagnosis of dysplasia by EC has been analyzed in detail $(6,27)$. Therefore, the current study was undertaken to evaluate and analyze the diagnoses of OML by EC and compare it with clinical, histopathological and flow cytometrical findings. Also, the misdiagnostic cases of EC were investigated clinically and flow cytometrically. The present results are based on the 275 cases and this study confirmed that the clinical features should remain the guiding factor in the management of any patients (2). The recognition of the earliest manifestations of dysplasia is difficult without histopathology although EC could be advantageous for early detection of some $\operatorname{OML}(5,6)$. In leukoplakia without dysplasia, $30 \%$ was misdiagnosed by EC. The study suggested that the surgeons' enthusiasm may be high to histologically evaluate these benign lesions, and the findings should also lead for correct diagnosis and further management.
The diagnosis of OML and the severity of dysplasia by EC alone remain a controversially discussed subject (7). This study has shown that the accuracy rate of diagnosing mild and moderate epithelial dysplasias is lower. However, several studies have shown the value of this method but cannot be a substitute for biopsy $(5,6,10)$. The atypical cells seen in the under-diagnostic cases were insufficient to make a clear cytological diagnosis. The study suggested that this striking feature might sometimes confuse the screeners and discourage the making of the correct diagnosis. It may be the result of sampling errors and underestimating the few atypical cells in the smears. Also, the presence of dysplasia in the stratum basale and lower layer of stratum spinosum in the early stages that limit the value of EC (7, 8, 21-24).

On the other hand, the over-diagnostic cases by EC were fewer compared to under-diagnostic ones. The study showed that the clinical findings mainly showed erythema, ulcerations and nodular outgrowths contributed to the misdiagnoses in dysplasias. These clinical features were not prominent features in some under-diagnostic cases. Ulcers may give the screeners unclear inflammatory atypia while the nodularity and erythematous features 
accentuate our image of malignancy. The smears showed adequate number of atypical cells with hyperchromatic nuclei and orange cytoplasms, which might raise the index of suspicion and the exaggeration of EC diagnosis. Candida was found in some cases that may contribute to the enthusiasm of EC over-diagnosis. It was reported that, among etiological factors, Candida infection seemed to play a role in malignant transformation, but the exact mechanism is still unknown (25).

Although the presence of these features is important clinical features of premalignancy and malignancy, there is likelihood EC screeners can overdiagnose these lesions when these features were present. Therefore, these features and the facts of misdiagnoses should be kept constantly in mind when examining cytological smears. The study also revealed that, in severe dysplasia, the cytological diagnosis correlated more to histopathological findings, compared to mild dysplasia, and the same tendency was also seen in the cervix (26). This may be due to the fact that the presence of dysplastic cells in upper stratum can be smeared more easily (8).

On the contrary, all EET or VC cases were incorrectly diagnosed by EC. The clinical findings were thought to decrease the access of the cytobrush during smear taking. Adequate amount of cells was smeared but the atypia did little to assist the EC diagnosis. In all OSCC cases, there were no misdiagnoses. Umiker et al. reported a 96.3\% accurate detection of oral cancer by EC, almost similar to the present study (5). These findings suggested that OML and the severity of dysplasia could not all be accurately predicted clinically and cytologically; therefore, biopsy was needed to confirm the diagnoses (27, 28).

Regarding FCMA, Johnson et al. has reported that the FCMA of cervical cancer exfoliated cells, had significantly decreased the incidence of false-negative and false-positive diagnoses and provided useful a prognosis (29). However, the values of D.I. and P.I. of leukoplakia without dysplasia and mild dysplasia were less significant that may suggest their similarities in histopathology, but significant between mild and moderate dysplasias. In addition, the differences between moderate and severe dysplasias were less significant that may suggest a greater malignant potential as the severity of dysplasia increases. In all cases of EET or VC was erroneously diagnosed by $\mathrm{EC}$ but the use of FCM revealed higher D.I. and P.I. closer to values of severe dysplasia and OSCC, and correlated with the histopathological findings. This concludes that the biological changes in the nuclei could not be detected by EC but FCMA could detect the DNA content. In contrast, the FCMA of OSCC was well correlated to cytological and histopathological findings. In this regard, a previous study by Dudzinski et al. demonstrated the high incidence of DNA aneuploidy in severe dysplasia and carcinoma exfoliative cells in cervical cancer, similar to the findings of this study (30). The study suggested that OSCC are well diagnosed by EC when the clinical features are easily identified.

FCM has shown to detect the DNA changes in $80.2 \%$ of some misdiagnostic cases. We had difficulties with the differentiation of a few cases of under- and over- diagnosed leukoplakia without dysplasia and dysplasias by FCM. It may be due to a few atypical cells exfoliated during smear taking or may be explained by the probable contamination from the oral microorganisms and debris in the mouth. All under- and over-diagnostic cases where the FCMA was insufficient to give significant results or support the EC and histopathological diagnoses were clinically followed up.

Our study showed that, compared FCM and EC, FCM assess DNA content, gave significant results. Therefore, the grading of dysplasia by EC remains one of the most obstacles in the diagnosis of OML. But dysplasias were less misdiagnosed by EC when the severity was increased. Despite their limitations, EC and FCM can still have a dramatic affect and advantageous on the OML diagnosis. The misdiagnostic cases of EC can be observed, posing a challenge for correct diagnosis and further management. Our FCM results have been shown to quantitatively analyze the DNA content of OML. Correlating FCMA with EC has been shown to be advantageous 
and FCM should not be considered a replacement for $\mathrm{EC}$, but an aid in the evaluation of OML. FCMA and EC are useful screening method and assist diagnosis but are not substitutes for biopsy.

\section{Acknowledgments}

The authors are grateful to Professor $\mathrm{H}$. Yamamoto (Department of Oral Pathology, Nihon University School of Dentistry at Matsudo) for his direction and helpful advice, and appreciate Professors H. Kozawa, T. Kondoh and M. Yamamoto (Departments of Histology, Cytology and Developmental Anatomy, Maxillofacial Surgery, Microbiology and Immunology, respectively, Nihon University School of Dentistry at Matsudo) for reviewing the manuscript. We thank Mr. Takashi Matsumoto and the staff of Department of Oral Pathology, Nihon University School of Dentistry at Matsudo for their continuous and kind support.

The study was supported by Suzuki Memorial Grant of Nihon University of Dentistry at Matsudo and the Ministry of Education, Culture Sports, Science and Technology, Japan, Grant-in-Aid for 20042006, 16591839, Scientific Research (C).

\section{References}

1. Casiglia J, Woo SB : A comprehensive review of oral cancer. Genet Dent, 49: 72-82, 2001.

2. Papanicolaou GN, Traut HF : Diagnosis of uterine cancer by the vaginal smear. The commonwealth fund. New York; 1943. p.1-7.

3. Papanicolaou GN, Traut HF : The diagnostic value of vaginal smears in carcinoma of the uterus. Am J Obstet Gynecol, 42 : 193-205, 1941.

4. The general rules for clinical and pathological management of uterine cervical cancer, 2nd ed., Japan society of obstetrics and gynecology. The Japanese Society of Pathology Japan Radiological Society. Kanehara \& CO. Tokyo ; 1997. p.20-21.

5. Umiker WO, Lampe I, Rapp R, Hiniker JJ : Oral smears in the diagnosis of carcinoma and premalignant lesions. Oral Surg Oral Med Oral Pathol, 13 : 897-906, 1960.

6. Shaklar G, Meyer I, Cataldo E, Taylor R: Correlated study of oral cytology and histopathology-report on 2, 052 oral lesions. Oral Surg Oral Med Oral Pathol, 25 : 61-70, 1968.

7. Abbey LM, Gunsolley JC, Page DC: Intraexaminer and interexaminer reliability in the diagnosis of oral epithelial dysplasia. Oral Surg Oral Med Oral Pathol, 80 : 188-192, 1968.

8. Maraki D, Becker J, Boecking A : Cytologic and DNA -cytometric of very early diagnosis of oral cancer. J Oral Pathol Med, 33 : 398-404, 2004.

9. Brickley MR, Cowpe JG, Shepherd JP : Performance of a computed simulated neural network trained to categories normal, premalignant and malignant oral smears. J Oral Pathol Med, 25 : 424-428, 1996.

10. Campisi G, Di Fede O, Di Liberto C : Incisional biopsy in oral medicine-punch vs traditional procedure. Minerva Stomatol, 52 : 481-486, 2003.

11. Riley RG, Mahin EJ, Ross W : Clinical applications of flow cytometry: In: The flow cytometer-historical developments and present applications. Igaku-Shoin Medical Publishers. New York ; 1993. p.3-9.

12. Riley RG, Mahin EJ, Ross W : Clinical applications of flow cytometry DNA analysis by flow cytometrygynecological malignancies. Igaku-Shoin Medical Publishers. New York; 1993. p.482-486.

13. Veltman JA, Hopman AHN, Bot FJ, Ramaekers FCS, Manni JJ : Detection of chromosomal aberrations in cytologic brush specimens from head and neck squamous cell carcinoma. Cancer, 81: 309-314, 1997.

14. Seoane J, Asenjo JA, Bascones A, Varela-Centelles PI, Romero MA: Flow cytometrical DNA ploidy analysis of oral cancer: Comparison with histologic grading. Oral Oncol, 35: 266-272, 1999.

15. Kahn MA, Dockter ME, Hermann-Petrin JM : Flow cytometrical analysis of oral premalignant lesions: a pilot study and review. J Oral Pathol Med, 21:1-6, 1992.

16. Schwartz JL, Muscat JE, Baker V, Larios E, Stephenson GD, Guo W, Xie T, Gu X, Chung FL: Oral cytology assessment by flow cytometry of DNA adducts, aneuploidy, proliferation and apoptosis shows differences between smokers and non-smokers. Oral Oncol, 39: 842-854, 2003.

17. Pindborg JJ, Reichart PA, Smith CJ, Van Der Waal I : Histological typing of cancer and precancer of the oral mucosa. 2nd ed., WHO. Springer. New York; 1997. p.21-25.

18. Barnes L, Eveson JW, Reichart P: Head and neck tumors. WHO. IARC Press. Lyon; 2005. p.178-181.

19. Takahashi M : Colour atlas of cancer cytology. In : Clatch RJ, Cytological DNA content and cell cycle analysis. Igaku-Shoin Medical Publishers. Tokyo; 2000. p.13-17.

20. Riley RG, Mahin EJ, Ross W : Clinical applications of flow cytometry-DNA analysis by flow cytometry. In : Riley RG, Mahin EJ, RossW. DNA ploidy and cell cycle analysis. Igaku-Shoin Medical Publishers. Tokyo ; 1993. p.269-275. 
21. Chandler JR: The nonvalue of oral cytology. Arch Otolaryngol, 84: 527-533, 1966.

22. Montgomery PW, Von Haam E: A study of the exfoliative cytology of oral leukoplakia. J Dent Res, 30 : 260-264, 1951.

23. Siliverman S, Becks H, Farber SM: The diagnostic value of intraoral cytology. J Dent Res, 37 : 195-205, 1958.

24. Scandler HC, Stahl SS: Exfoliative cytology as a diagnostic aid in the detection of oral neoplasms. J Oral Surg, 16 : 414-419, 1958.

25. McCullough M, Japer M, Barrett AW: Oral yeast carriage correlated with presence of oral epithelial dysplasia. Oral Oncol, 38 : 391-394, 2002.

26. Kashyap V, Das DK, Luthra UK: Microphotometric nuclear DNA analysis in cervical dysplasia of the uterine cervix: Its relation to the progression to malignancy and regression to normalcy. Neoplasm, 37: 497-500, 1990.

27. Pindborg JJ, Reibel J, Holmstrup P : Subjectivity in evaluating oral epithelial dysplasia, carcinoma in situ and initial carcinoma. J Oral Pathol, 14: 698-708, 1985.

28. Sciubba JJ : Oral leukoplakia. Crit Rev Oral Biol Med, 6: 147-162, 1995.

29. Johnson TS, Katz RL, Pershouse M : Flow cytometric applications in cytopathology. Anal Quant Cytol Histo, 10 : 422-459, 1988.

30. Dudzinski MR, Haskill SJ, Fowler WC, Currie JL, Walton LA: DNA content in cervical neoplasia and its relationship to prognosis. Obstet Gynecol, 69 : 373377, 1987. 